\title{
Projeto, projeção e desejo: o design e o futuro
}

Project, projection and desire: design and the future

\author{
MOON, Rodrigo; UNESP - Bauru \\ rmdbmoon@gmail.com \\ ROSSI, Dorival. Dr; UNESP - Bauru \\ bauruhaus@yahoo.com
}

\begin{abstract}
Resumo
Entender o design filosoficamente significa entender o projeto enquanto solução de uma problemática, enquanto ferramenta rumo a uma finalidade pré-determinada. Projetar significa determinar uma projeção no futuro e traçar os caminhos, os meios, para um fim designado. Não podemos ignorar o designer enquanto máquina subjetiva já consolidada, como veículo para as ideias se estruturarem rumo à solução. Desta forma, pretendemos compreender o exercício do designer através de conceitos da filosofia, como forma de fazer referência a processos abstratos e complexos que operamos em nossa prática. E isto implica considerar o desejo enquanto construção, enquanto forma de estruturar os caminhos pela subjetividade. Assim, encarando o exercício do designer como uma projeção futura de acontecimentos, experimentação complexa de fatores e proposição de meios, sempre trabalhando nas ligações, podemos definir o design como ferramenta complexa e projetual capaz de estruturar qualquer sistema humano e otimizá-lo, alterá-lo ou modelá-lo.
\end{abstract}

Palavras Chave: Design; Filosofia; Projeto.

\begin{abstract}
To philosophically understand design means to understand the project as a way to resolve problems, as a tool towards a predetermined goal. To project means to determine a future projection and to trace the paths, the means, to reach a desired end. We cannot ignore the designer, as an already aggregated subjective machine, as a vehicle for the ideas to be structured towards the solution. In this way, we aim to understand the designer practice through philosophic concepts, as a manner to reference abstract and complex processes. This implies to consider the desire whilst a construction, whilst a form to structure the paths through the subjectivity. In this way, facing the designer practices as a future projection of happenings, complex experimentations of factors and the proposition of means, always acting on the point of connections, we can define design as a complex and projective tool capable of structuring any human systems, and optimize, alter and model it.
\end{abstract}

Keywords: Design; Philosophy; Project. 


\section{Design e o designer}

Cabe fazer uma introdução à problemática deste artigo, no intuito de situar o leitor para com as abordagens que tomaremos. Conhece-se muito bem a atuação do designer e toda a literatura que se desenvolveu em torno do design como área do saber, emancipado das artes, da arquitetura e das engenharias de um modo geral. Contudo, pensamos que restam alguns fantasmas que se incorporaram em nossa concepção de design e da atuação do designer. Pretendemos, aqui, inicialmente, denotar um novo paradigma: o da organização e da complexidade. Para tal, será necessário fazer um resgate conceitual do que pretendemos com nossos conceitos filosóficos enquanto linguagem.

Primeiramente, antes de dizer de fato o que o design pode ser, queremos trazer uma discussão de ordem linguística: 'design', por não ser palavra derivada do português, não possui definição fiel nem raiz etimológica na qual podemos buscar um sentido próprio através de seus radicais. Assim, podemos pensar no design como sendo uma tela, mas bem longe de estar em branco. Nossa tela já tem um grande Pollock sobre ela: pontos diversos, linhas que unem, organizações formadas ao acaso. Temos uma grande trama de acontecimentos, mas nenhum território externo a tudo isso. Parece que não se conectam estes diversos microterritórios do design. Para tal, nosso alvo será especificamente este (e, portanto, nossa hipótese): se existem diversas atuações - como produto, gráfico, interfaces, digital, superfícies, etc... - que se configuram sob o guarda-chuva do design, há de se ter um conceito central de Design que derive todas as classificações.

E as pistas que coletamos ao longo de nossa pesquisa nos apontam para o aspecto organizativo do designer: não importa realmente a matéria a ser trabalhada nem o resultado específico (pois estes são variáveis), mas o processo de organização das partes que são agenciadas durante um projeto, seja na elaboração do problema a ser solucionado, seja na própria solução. Organizar é alterar a disposição de um sistema através de seus parâmetros: composição, conectividade, estrutura, integralidade e funcionalidade, para que assuma relações de coesão e coerência (VIEIRA, 2015). Podemos entender a organização pela teoria da informação:

As mensagens são em si uma forma de padrão e de organização. Com efeito, é possível tratar conjuntos de mensagens como tendo uma entropia ${ }^{2}$, tais como conjuntos de estados do mundo exterior. Assim como a entropia é uma medida da desorganização, a informação transmitida por um conjunto de mensagens é uma medida de organização. (PIGNATARI, 1981. p. 48)

Assim, consideramos que a coleta de informações e a organização de sistemas, pelos parâmetros elencados acima, são alvo do exercício do designer - seja em mensagens visuais ou sonoras, estruturas físicas para produtos ou espaços, ou mirando atuações estranhamente

\footnotetext{
1 “A ideia de informação está sempre ligada à ideia de seleção e escolha. Informação, aqui, se refere, não a que 'espécie de informação', mas a 'quanta informação'. Só pode haver informação onde há dúvida e dúvida implica na existência de alternativas - donde escolha, seleção, discriminação. De outro lado, lembramos ainda que os sinais transmitem ou transportam informação como um vagão transporta mercadorias. [...] Informação, pois, pode ser entendida como instruções seletivas. Para usar a definição de G. A. Miller: Informação é o de que necessitamos quando devemos fazer uma escolha." (PIGNATARI, 1981. p. 40)

2 "O conceito de entropia surgiu incialmente na termodinâmica, para indicar a medida estatística da perda de energia em certos processos físicos irreversíveis. Assim é que, pela segunda lei da termodinâmica, a quantidade de calor na qual se transformou uma certa quantidade de trabalho não pode mais ser inteiramente recuperada na mesma quantidade de trabalho originária." (Ibid, p. 47)
} 
controversas, como sobrancelhas ou bolos. Assim, design como ferramenta para, intencionalmente, organizar heterogeneidades sob o regime de uma significação e uma relação das partes. E, por tal, essa forma de organização por sintaxes e semânticas tem laços estreitos com linguagens, se considerarmos os fundamentos de uma semiótica (ROSSI, 2003), e assim podemos falar em uma dita "linguagem do design". Por isso que sempre se pauta um conceito nas obras ou projetos: qual será a diretriz conceitual, ou leia-se de outra forma, qual será a significação a ser transmitida entre emissor e receptor por meio de uma linguagem das organizações, das informações? E quais os canais que nos utilizaremos para que esta informação seja transmitida? Daí emergem todas as áreas as quais mencionamos enquanto meios de transmissão: o design gráfico, de produtos, de interfaces, e quaisquer plataformas que permitam o designer operar, por projetos, suas organizações. Se a linguagem é o design, a construção dos discursos serão as formas de dizer do designer: o projeto, que rege a sintaxe das partes, das matérias heterogêneas, e a comunicação, que rege a semântica para com o todo que envolve determinado sistema.

"Coesão e estrutura se aproximam da ideia de sintaxe; coerência e organização de semântica. É a coerência sistêmica que dá sentido às partes, constituindo o substratum de toda significação, logo da dimensão semântica" (VIEIRA, 2015. p. 208).

De fato, toda obra, todo projeto, e todo processo em design necessariamente devem ser organizados sistematicamente pela coesão de suas partes, seja numa mensagem, seja em uma estrutura física, virtual (LEVY, 2011), enfim; e uma coerência do todo para com sistemas alheios, como a física que rege os materiais e todo o sistema de significações que possam se impor ao designer e ao objeto através da cultura. Pensar sobre o projeto nos faz questionar como tudo começa: pois, esta necessidade projetual, esta fagulha que desperta e demanda o uso do projeto por um designer, nasce de uma perturbação, ou fonte de ruído, à qual comumente nos referimos enquanto problemática (ou briefing).

Sempre se pautou o design enquanto solução de problemas, de empecilhos, ou ainda a detecção dos mesmos. O designer lida com a problemática diariamente, é a partir dela que nasce qualquer organização ou qualquer adequação, otimização. Não existe um designer que aja sem problemas, não existe projeto sem finalidades (mesmo que seja o próprio processo). Se se projeta, se projeta algo e, necessariamente, para fins humanos. Solucionar é reorganizar. Se um sistema se encontra com ruído, desordem ou falha de funcionamento, evocamos um designer para que conserte, melhore, ou reformule este sistema, operando uma dissolução do todo em partes, em detrimento de uma resolução em novo sistema. E aqui não falamos de estados ou sistemas congelados, necessariamente falamos sobre tempo decorrido: "Processos são cadeias de eventos e assim são representáveis no espaço de estados como trajetórias" (VIEIRA, 2015. p. 56). Assim, a solução de um problema é necessariamente a reorganização e tradução entre sistema perturbado e sistema ordenado, transformação de ruído em informação através de processos de coesão e coerência, inerentes ao projeto.

Cabe dizer que não estamos falando de sistemas naturais regidos por processos estocásticos ${ }^{3}$; estamos falando de sistemas humanos artificiais, criados por cadeias de significações e ressignificações das informações ao longo das eras, decorrentes das interações entre esfera

\footnotetext{
${ }^{3}$ Dentro da teoria das probabilidades, um processo estocástico é uma família de variáveis aleatórias representando a evolução de um sistema de valores com o tempo. É a contraparte probabilística de um processo determinístico. "As linguagens naturais são processos estocásticos aproximadamente ergódicos (GOLDMAN, 1958, p. 18 In. VIEIRA, 2015, p. 197)"
} 
cultural e linguística, que culminaram nos sistemas humanos atuais que regem nossas sociedades. E se falamos sobre processos humanos, pautamos uma finalidade implícita, uma intencionalidade subjetiva. Intenção, aqui, tida como diretriz para um processo em direção a um fim. Falamos aqui do projeto como afunilamento de possíveis.

Dessa forma, podemos emancipar o projeto como algo que extravasa o designer ou qualquer profissão projetiva. Estamos lidando com uma dimensão de um projeto sistêmico e complexo. Depende da estruturação, virtual, de um estado possível de qualquer sistema, ao qual o designer tem determinado em sua mente ou em suas ferramentas virtuais - sejam softwares, desenhos em papel, discursos imaginativos, ou ainda projetos escritos. Estas ferramentas acabam vinculando este objeto virtual, este estado futuro, ao presente, de forma que existe um processo imaginativo que interliga, por semelhanças, uma proposição atual a uma virtual. Assim, necessariamente, todo designer deverá lidar com sua imaginação para alcançar estes estados virtuais. Mas oras, do que falamos exatamente quando situamos um universo imaginário e possível?

\begin{abstract}
Nessa posição de limite e de condição (aquilo sem o que, e, aquém do que não se pode conhecer), a semelhança se situa do lado da imaginação ou, mais exatamente, ela só se exerce apoiando-se nela. Com efeito, se se supõem na cadeia ininterrupta da representação, impressões por mais simples que sejam, e se não houvesse entre elas o menor grau de semelhança, não haveria qualquer possibilidade para que a segunda lembrasse a primeira, a fizesse reaparecer e autorizasse assim sua reapresentação total, que não poderia sequer ser percebida visto que uma representação jamais teria ensejo de se estabelecer num lugar, de ressuscitar outra mais antiga e de se justapor a ela para dar lugar a uma comparação; a tênue identidade necessária a toda diferenciação sequer seria dada. [...] Sem imaginação não haveria semelhança entre as coisas. (FOUCAULT, 1992. p. 82)
\end{abstract}

Este estado de possíveis só se torna palpável em virtude de uma semelhança entre a atualidade e a possibilidade (virtualidade). Através das similitudes, mais especificamente as analogias, juntamos duas diferenças sob a figura de uma semelhança, que une sob a premissa de um processo de significação, e traduz um estado no outro. E aqui é que o design enquanto linguagem ganha vida: ele será responsável pela tradução entre o tempo presente e um tempo possível, arraigado de disrupções e dissimulações que sempre arrastarão a possibilidade para um ruído, para uma des-determinação dos estados futuros. Linguagem, pois, há de se ter semelhança entre um estado e outro no processo de reorganização, entre um possível e outro, entre uma representação do sistema em determinado estado e se seguinte. E o projeto é a ferramenta necessária de controle dos possíveis para que o designer tenha confiança para enunciar que a finalidade é que conduz o processo: função teleológica do projeto. Assim, elencada a finalidade, este objeto virtual, o projeto se encarregará do processo de atualização ${ }^{4}$ (LEVY, 2011), de tornar o virtual em atual.

\title{
2 Projeto e o futuro
}

Quando se pensa em projeto, normalmente evocamos a figura de uma metodologia e uma finalidade: de um metaprojeto organizacional dos processos, de pessoas que o executem (energia que execute os trabalhos) e o estado virtual a ser atualizado. Entende-se o caminho e se valoriza o tempo e os meios utilizados. O processo hoje supera a finalidade em importância, pois, quanto mais

\footnotetext{
4 "A atualização é criação, invenção de uma forma a partir de uma configuração dinâmica de forças e finalidades" (LEVY, 2011)
} 
complexos os fins, mais trabalhosos serão os processos. Expandindo os possíveis, e aqui podemos fazer uso da ficção para exemplificar, o designer poderá de fato imaginar qualquer futuro para qualquer sistema: semelhanças das mais absurdas, contos fantásticos ao estilo de Borges. A estruturação de uma realidade possível, a simulação de mecânicas e a proposição de processos pela ficção se assemelha muito ao processo de criação virtual do designer. A diferença é que um se utiliza da linguagem literária e outra do design. Isto acarreta em um ponto importante: a complexidade do projeto. Quanto maior for a diferença entre fim e começo, entre atual e virtual, maior será a necessidade de trabalho - e consequente energia - empregado no processo.

Dado um sistema em seu estado atual, o designer poderá analisar as partes, avaliar sua coesão, olhar para o todo, analisar sua coerência e fazer um diagnóstico de possíveis: poderia, este, ser outro sistema? Imediatamente, inaugura-se um processo de ideação, para que se atribua a finalidade específica: qual é o estado ideal para este sistema, dadas as circunstâncias atuais e todas as possibilidades adjacentes, comumente chamadas de referências, que denotam um afunilamento das finalidades? Através de um processo de virtualização (LEVY, 2011), problematização, é possível transformar o que é atual em virtual, de tal forma que, ao se perguntar se o sistema poderia ser diferente, imediatamente se virtualiza toda sua estrutura para que se trabalhe todas as possíveis diferenciações, reconexões entre as partes, reorganização de funcionalidades, em direção à finalidade específica. Em suma, o processo de problematização força uma coerência entre todos os possíveis do sistema e o escopo delimitado, de tal forma que se busca o caminho mais curto ou mais preciso para que se atinja o objeto virtual e o atualize.

Quando pensamos em finalidades, inevitavelmente queremos remeter a uma balística ${ }^{5}$ de possíveis: que se trace o alvo, se mire e acerte. Há de se considerar resistência do ar, vento, obstáculos, e qualquer interferência externa ao projétil. Este tipo de pensamento que se lança ao futuro é traiçoeiro e constitui a essência de um pensamento complexo na contemporaneidade. Considera-se as relações entre os saberes, entre as esferas humanas, entre as atuações; a liquidez contemporânea configura um mar das relações do homem, às quais um projeto apenas remete à construção de aquedutos, como fizeram os romanos, na esperança de conduzir certos fluxos e consolidar sua importância dentre a multiplicidade caótica. Ao problematizar algo, força-se um processo de sublimação de tudo o que é material para que todas as moléculas virem energia, potência, força e tendência a uma atualização, a uma emancipação de toda a problemática, para que enfim se crie algo novo. E dependendo do projeto, a complexidade pode ser exponencial, pois quanto mais problemas se congregam, maior a dificuldade de coerência múltipla entre todos os parâmetros que determinarão a seleção de um grupo de possíveis que serão considerados enquanto fins dos processos projetuais.

Claro, aqui deveremos também diferenciar toda a complexidade dos múltiplos projetos que um designer pode desenvolver: a criação de uma marca e a multiplicidade de interpretações que o observador terá; as possibilidades de falha técnica de uma estrutura de madeira, seja uma mesa, uma cadeira ou uma instalação; sistemas escolares e todo o fluxo lógico de pessoas, bem como os desvios e lentidão nos corredores pelo movimento intenso de pessoas, geometrização das salas de aula e posição hierárquica do professor em relação aos alunos. São inúmeras as possibilidades de interações entre componentes, entre as 'moléculas de água do fluxo do aqueduto'. A metáfora

\footnotetext{
5 “não surpreende, pois, que a máquina de guerra seja a invenção dos nômades pecuaristas: a pecuária e o adestramento não se confundem nem com a caça primitiva, nem com a domesticação sedentária, mas são precisamente a descoberta de um sistema projetor e projétil." (DELEUZE, GUATTARI, 1997. p. 61)
} 
apenas confirma que quanto mais constrito for o caminho, menor a possibilidade de erro, ruído, vazamento. O fluxo contido é característica de um designer projetando informação. E quando consideramos sistemas ativos e reativos, em movimento, a complexidade tende sempre a crescer. Projetar um móvel difere da complexidade de um sistema escolar, tanto pela conglomeração de diversas áreas do saber e da atuação humana, quanto à reatividade do sistema a qualquer modificação de sua matéria viva, humana.

Assim, podemos pensar que conforme a complexidade cresce, surge uma necessidade de experimentação, ante uma previsão. A previsão é limitada e depende de cálculos matemáticos, projeções futuras que devem ser precisas a ponto de que o cano seja estrito, que passe apenas uma molécula. Em contrapartida, uma experimentação desta complexidade permite simular o sistema projetado e vê-lo reagir, daí surge toda a beleza da prototipagem enquanto afunilamento de possíveis pela prova viva de suas interações. Não há necessidade de prever e coibir; apenas de experimentar e reagir. A previsão terá como alvo determinar um caminho certeiro para o projétil; a experimentação consiste em tentativa e erro, em fazer, observar, pensar e refazer até que se melhore a mira e acerte o alvo. E nós, designers, estamos acostumados com tal feitio. Testamos a todo momento nossos objetos: você consegue ver um elefante nessa marca? O que você vê aqui então? Esta cadeira está confortável? Este caminho te direcionou para aquele lugar em específico?

Projetar algo para um futuro implica em saber o que se passa no contemporâneo, determinar as viabilidades e determinações de hoje no amanhã. Assim, queremos dizer que o exercício do designer, por lidar fortemente com esta ideia de futuro, detém importância tremenda dentre as atuações humanas, porque seremos responsáveis pelos moldes do amanhã, pela ficção que antevê e precipita, determina uma probabilidade. O designer tem o poder do projeto e consequentemente o poder do futuro. Porém, existe a possibilidade de reverter a ordem dos acontecimentos durante seus processos, e que seus produtos podem ser organizados de tal forma que o atual imite o virtual. Baudrillard discorre sobre essa precessão da ficção ao real:

\begin{abstract}
Obcecante conjunção da Síndrome da China e de Harrisburg. Mas será tudo isto involuntário? Sem discernir elos mágicos entre o simulacro ${ }^{6}$ e o real, é claro que a Síndrome não é estranha ao acidente «real» de Harrisburg, não segundo uma lógica causal, mas pelas relações de contágio e de analogia silenciosa que ligam o real aos modelos e aos simulacros: à indução do nuclear pela televisão no filme responde, com uma evidência perturbadora, a indução pelo filme do acidente nuclear de Harrisburg. Estranha precessão de um filme sobre o real, a mais espantosa à qual nos foi dado assistir: o real respondeu, ponto por ponto, ao simulacro, inclusivamente no carácter suspensivo, inacabado, da catástrofe, o que é essencial do ponto de vista da dissuasão: o real acomodou-se, à imagem do filme, para produzir uma simulação de catástrofe.
\end{abstract}

Daí a inverter a nossa lógica e a ver na Síndrome da China o verdadeiro acontecimento e em Harrisburg o seu simulacro, não vai mais que um passo que se deve dar alegremente. $\mathrm{E}$ pela mesma lógica que a realidade nuclear procede no filme do efeito televisão e que Harrisburg procede na «realidade» do efeito de cinema Síndrome da China. (BAUDRILLARD, 1991. p. 73)

Esta inversão lógica entre real e possível, entre simulação e atual é uma discussão perfeitamente plausível quando se pensa na complexidade destas estruturas virtuais. Se Baudrillard nos diz que é perfeitamente possível inverter a relação causal entre um acontecimento real e um

\footnotetext{
6 "O simulacro nunca é o que oculta a verdade - é a verdade que oculta que não existe. O simulacro é verdadeiro." (BAUDRILLARD, 1991, p. 7)
} 
fictício, é porque, numa lógica temporal, a existência da simulação (virtual) precede sua atualização. Assim é espantoso pensar num projeto, numa organização, numa informação ficcional, imaginativa e criativa, como modelo, como simulacro do próprio real e, portanto, com potência de moldar a própria realidade pelo tipo de reação dos sistemas humanos ao acontecimento já experimentado enquanto simulação. De tal forma o projeto organizativo pode agir a antever acontecimentos reais e servir de referência a qualquer interpretação de uma realidade que se constrói nos moldes de uma invenção. A possibilidade de simular propostas projetuais permite ao designer ter certeza de suas escolhas submetendo-as ao juízo matemático de algoritmos que tentam emular a realidade um juízo objetivo? Este caráter da simulação, desta estruturação virtual de acontecimentos, de necessidades ou de uma proposição qualquer, corrobora para uma intervenção nas formas de semelhanças que se fazem entre o imaginário e a realidade nas mais diferentes subjetividades. A simples colocação em discurso de um possível determina esta simulação, e determina assim um campo de possíveis soluções, reações, a esta problemática. Como uma célula de memória do sistema imunológico: a vacina enquanto simulação e a reação ao vírus enquanto atualização.

Esta relação entre projeto e futuro é de vital importância quando se considera que o designer projeta para sistemas humanos: se o projeto privilegia alguma finalidade não humana, como capital ou industrial, de certo o imaginário se adequará a este modelo e as subjetividades serão esquecidas. É de vital importância, e Guattari nos alerta sobre isso: é preciso recentralizar as finalidades de agenciamentos ${ }^{7}$ produtivos para que se privilegiem a emancipação de subjetividades como as novas formas de projetar para nossos sistemas humanos, em resgate, por exemplo, da dita 'cidade subjetiva', na qual os fluxos e agenciamentos coletivos de enunciação se desviem de finalidades outras em detrimento de uma melhor ecologia social, privilegiando, acima de tudo, o devir da vida (GUATTARI, 1990). Ele nos dá o exemplo de que a cidade é plataforma de subjetivação de todo indivíduo, e há de se pensar nelas como passíveis de uma reestruturação. Assim, que se construam novas formas de operar nossos ambientes, ainda mais quando nos situamos em um momento de intensa desconstrução de nosso passado, de nossos valores positivistas da era industrial e das finalidades capitalistas e esteticistas de um hedonismo emancipado pela produção em massa de desejos, pelas mídias como a TV e o cinema. O designer terá papel decisivo nas novas instaurações das ecologias do homem, propondo uma recentralização das finalidades produtivas para com um futuro projetado e humano.

\section{Desejo e a subjetividade do designer}

Tendo em mente que o projeto mira o futuro como em uma balística; tendo em mente todo o processo de criação, de atualização do objeto virtual em atual, não podemos ignorar a intencionalidade de quem executa o processo projetual, e, assim, se faz necessário colocar a subjetividade do designer como primeiro patamar para qualquer ação projetual. Se buscamos um vocábulo para expressar toda a complexidade de um projeto enquanto processo de atualização, inversão entre problema-solução, estaremos falando de uma construção desejante. E teremos, em Deleuze, uma diretriz conceitual para tomar desejo enquanto construção de um possível:

Quando uma mulher diz: desejo um vestido, desejo tal vestido, tal chemisier, é evidente que não deseja tal vestido em abstrato. Ela o deseja em um contexto de vida dela, que ela vai organizar o desejo em relação não apenas com uma paisagem, mas com pessoas que

\footnotetext{
7 Podemos definir agenciamento como a forma de organizar o movimento, como a conjunção de fatores que, em conjunto, definem as formas pelas quais se atualiza alguma virtualidade. Se todo desejo corre para um agenciamento, é porque o movimento desejante se faz pela organização de meios, fins e vontades como produto de uma subjetividade.
} 
são suas amigas, ou que não são suas amigas, com sua profissão, etc. Nunca desejo algo sozinho, desejo bem mais, também não desejo um conjunto, desejo em um conjunto. Podemos voltar, são fatos, ao que dizíamos há pouco sobre o álcool, beber. Beber nunca quis dizer: desejo beber e pronto. Quer dizer: ou desejo beber sozinho, trabalhando, ou beber sozinho, repousando, ou ir encontrar os amigos para beber, ir a um certo bar. Não há desejo que não corra para um agenciamento. O desejo sempre foi, para mim, se procuro o termo abstrato que corresponde a desejo, diria: é construtivismo. Desejar é construir um agenciamento, construir um conjunto, conjunto de uma saia, de um raio de sol... De uma rua. É isso. O agenciamento de uma mulher, de uma paisagem. De uma cor, é isso um desejo. É construir um agenciamento, construir uma região, é realmente agenciar. $\mathbf{O}$ desejo é construtivismo. (DELEUZE, 2001) (grifo dos autores)

Deleuze nos arrasta para uma compreensão do movimento humano através do desejo. Em O Anti-Édipo, em conjunto com Guattari, conceituam o devir como o tornar tornando-se, e que o motor central desse movimento de reinvenção constante é o desejo. Desejo enquanto forma de construir os caminhos baseados no que já se foi, no que se é e, ao contrário da falta, que Freud e Platão sempre impuseram sobre o ato de desejar, este movimento desejante é a mera vontade que se tem de viver. "Criar, para nós, é viver, e os cientistas e artistas são aqueles que mais intensamente estão sujeitos a esse impulso vital." (VIEIRA, 2015, p. 151) Sempre se deve buscar agenciamentos que agradem determinada subjetividade, cada qual em seu plano. O designer é íntimo do desejo pois não se faz nada sem a devida vontade, sem o devido agenciamento produtivo, sem a colocação contextual da produção em coletividade, em um corpus desejante. Pois, "O desejo é a potência produtora que agencia as relações, sob graus de velocidade ou lentidão, conforme a velocidade do fluxo e a intensidade do projétil" (BORGES, 2008). E aqui não falamos somente de um desejo sexual, um desejo em busca do prazer ou de qualquer eroticidade. Focamos no desejo enquanto motriz, enquanto a forma pela qual uma subjetividade projeta uma finalidade: aceleração de fluxos. Por tal, se se deseja produzir um sistema determinado que corresponda à solução de uma problemática levantada, é de fato o desejo que construirá uma assemblage ${ }^{8}$ de corpos, das mais diferentes matérias de expressão, em busca de movimentar todo este conjunto rumo a um futuro projetado e que durante todo o processo de tornar-se, vai tornando-se. E tomaremos a subjetividade enquanto um conjunto, com relações exteriores, composição e altíssima fluidez das partes, como instância que inaugura qualquer intencionalidade, qualquer vontade, que enuncia as mais diversas organizações das informações. Para tal, convém definir junto à Guattari uma subjetividade:

\footnotetext{
Proporemos então operar um descentramento da questão do sujeito para a da subjetividade. O sujeito, tradicionalmente, foi concebido como essência última da individuação, como pura apreensão pré-reflexiva, vazia, do mundo, como foco da sensibilidade, da expressividade, unificador dos estados de consciência. Com a subjetividade, será dada, antes, ênfase à instância fundadora da intencionalidade. Trata-se de tomar a relação entre o sujeito e o objeto pelo meio, e de fazer passar ao primeiro plano a instância que se exprime (ou o interpretante da tríade de Pierce). A partir daí se recolocará a questão do conteúdo. Este participa da subjetividade, dando consistência à qualidade ontológica da expressão. É nessa reversibilidade do conteúdo e da expressão que reside o que chamo de função existencializante. Partiremos, então, do primado da substância enunciadora sobre o par expressão e conteúdo. (Guattari, 1992, p. 35)
}

\footnotetext{
${ }^{8}$ Assemblage é um termo confuso e difícil de definir. Dentro de Mil Platôs, Deleuze e Guattari expõe um quadro das assemblages como forma de analisar o social por meio das relações de exterioridade e impermanência dos componentes de um dado sistema. Assim, tomaremos como definição uma montagem heterogênea de elementos que, em sua imanência mantém uma relação de exterioridade com sistemas alheios e que estas relações determinam a interioridade do dado sistema. Um sinônimo seria: constelação.
} 
Esta assemblage que reúne tanto a produção agregadora de um agenciamento quanto as conexões estabelecidas entre elas, categorizam esta forma de construtivismo de uma subjetividade, instância fundadora da intencionalidade pelo desejo. Em outros termos: o designer, guiado pelo desejo de expressar, de exprimir, enquanto cria-tura, fará conexão entre todos os corpos conceituais, ferramentais e virtuais que possui em seu acervo em busca de uma estrutura virtual, aqueduto que possibilite a condução dos fluxos criativos e produtivos de um projeto em direção à finalidade elencada e especificada. Isto significa que o próprio designer é plataforma projetual para os caminhos produtivos de um desejo, de um projeto. Considerando algo como um fluxo transversal ${ }^{9}$, que perpasse os mais diferentes conceitos, saberes e gostos, o designer enuncia suas ações pela possibilidade de modular as velocidades e intensidades criativas e produtivas que se empregam em direção à solução de uma problemática - voltamos à linguagem.

Mas não necessariamente de apenas um designer se faz um agenciamento produtivo: considerando a complexidade do projeto em questão, haverá necessidade que nesta conjunção se unam diversas subjetividades, das mais diversas composições e matérias de expressão às quais haverão de interagir em busca das relações necessárias para que a estrutura se mantenha estável. O que se faz presente nesta discussão é exatamente a coesão dos diversos corpos heterogêneos necessários a um projeto. Considerando a complexidade de um sistema educacional, por exemplo, um designer não poderá somente fazer uso de seu acervo específico para projetar o sistema em toda a sua integridade. Pedagogia, arquitetura, entre diversas áreas, serão requisitadas a comparecer e se fazerem presentes e expressivas. Qual será o papel do designer então neste tipo de projeto? Da mesma forma que a imaginação e a semelhança serão necessárias para unir dois estados diferentes de um mesmo sistema, o designer será figura da relação entre as diversas partes de um quebra-cabeça projetual, em busca de uma coesão das partes. A coerência será realizada pelas partes em específico: o pedagogo defenderá seus conceitos e suas ferramentas de matéria humana como se defende o desejo de se expressar; o arquiteto defenderá o uso coerente de espaços em busca da melhor adaptação do ambiente pedagógico e ao fluxo de pessoas; e por fim, o designer será responsável por manter coesas estas diferentes partes em detrimento da finalidade.

E os sistemas humanos serão os mais diversos, de tal forma que se projetarmos uma campanha visual, ainda há necessidade de se fazerem coesas todas as propostas, as informações e as mídias utilizadas. A coerência será cultural e de expressão humana, de tal forma que o acervo de signos e significações utilizadas pelo designer devem se fazer presentes nas subjetividades que interpretam.

O desejo do designer será impulsionado pela mesma problemática do projeto, de tal forma que o designer deverá viver e se fazer inteiriço nas enunciações que promove, sejam elas de cunho discursivo, produtivo ou criativo. A vivência do designer é através da problemática, por tal que se costuma dizer que o ofício central do designer se resume à resolução de problemas. Mas não apenas a isso; considerando o paradigma contemporâneo, no qual o designer remete também a uma pura expressão subjetiva, desviando-se de finalidades ditas humanas, resgatamos Guattari para nos salientar que as produções autorais e artísticas mantêm uma finalidade sistêmica para com toda a composição da subjetividade, determinando pela coesão das partes uma finalidade, complexa e muitas vezes desconhecida, expressiva. Nenhum projeto se mantém sem apontar ao futuro de

\footnotetext{
${ }^{9}$ Guattari, no contexto da psicanálise, conceitua a transversalidade para propor que a subjetividade não se faz apenas por estratos diferenciados das ciências sociais e humanas, mas sim de algo que perpasse tudo isso e produza um híbrido, de tal forma que o transversal perpassa matérias heterogêneas e não somente dentro de um plano.
} 
forma teleológica porque é decorrente de um desejo, de um objeto a ser construído.

Nos utilizamos de diversas máquinas em nosso movimento desejante, sempre perpetuando enunciações, estados congelados de uma subjetividade em movimento; sejam elas projetuais, na ordem organizacional, no nível de um metaprojeto; sejam elas tecnológicas, permitindo produções complexas, como softwares de modelagem 3D, bitmap, renderização e prototipação; sejam elas expressivas, pela forma como a informação é veiculada. Qualquer máquina pode ser utilizada por uma subjetividade em seu movimento desejante, e, por tal, é necessário figurar exercícios cada vez mais díspares e múltiplos do designer. Se a premissa é organizacional, da ordem da informação e do ineditismo, permite-se até mesmo a incorporação do ruído enquanto máquina diferencial, enquanto forma de se colocar, subjetivamente, no processo. O ruído de uma obra será todas as informações não necessárias à finalidade, mas que não intervém no percurso e muito menos na solução. A colocação do designer em suas produções criativas implica necessariamente na ideia tida. Deleuze nos diz:

Se fazemos ou queremos fazer cinema, o que significa ter uma ideia? O que acontece quando dizemos: "Ei, tive uma ideia"? Porque, de um lado, todo mundo sabe muito bem que ter uma ideia é algo que acontece raramente, é uma espécie de festa, pouco corrente. E depois, de outro lado, ter uma ideia não é algo genérico. Não temos uma ideia em geral. Uma ideia, assim como aquele que tem a ideia, já está destinada a este ou àquele domínio. Trata-se ou de uma ideia em pintura, ou de uma ideia em romance, ou de uma ideia em filosofia, ou de uma ideia em ciência. E obviamente nunca é a mesma pessoa que pode ter todas elas. As ideias, devemos tratá-las como potenciais já empenhados nesse ou naquele modo de expressão, de sorte que eu não posso dizer que tenho uma ideia em geral. Em função das técnicas que conheço, posso ter uma ideia em tal ou tal domínio, uma ideia em cinema ou uma ideia em filosofia. (DELEUZE, 1999)

Assim, é inevitável que a ideia tida carregue em si as características de quem a teve. Considerar o conjunto do desejo e a linguagem própria de cada ideia elaborada enquanto enunciação virtual, significa considerar que o designer, para ter boas ideias, deve possuir, enquanto linguagem do projeto, capacidade de unir as mais diversas ferramentas, palavras, materiais, e que a força de sintaxe, de coesão entre as diversas matérias heterogêneas de expressão será, então, o conjunto da subjetividade do designer. E todas as ferramentas utilizadas configuram, assim, a estrutura primordial de uma ideia a ser construída por ação e métodos projetuais, por congregações de fatores e relações especificamente designadas para compor este projétil, a ser agenciado pelo próprio designer ou pela equipe designada a desenvolver o projeto. Ter uma ideia para um designer é ter de configurar de forma coesa e coerente uma miríade de matérias heterogêneas, que se aliam em uma estrutura projetual lançada no futuro. Ter uma ideia para um designer é ter um vislumbre, ao longe, de uma possibilidade: "já sei!" significa saber, a partir da ideia, como as coisas se relacionam, como se organizam. A ideia do designer é a informação em sua mais pura essência organizacional e projetiva (virtual). Assim, através da conjunção das diversas matérias de uma subjetividade, as técnicas e máquinas que domina, e o contexto das enunciações coletivas que determinarão o projeto. Não é mais necessário pensar que boas ideias vêm para quem o 'dom', mas sim para quem tem as condições de concebê-las.

\section{Considerações finais}

Dessa forma podemos compreender que se buscamos, de forma complexa, definir o movimento do projeto, só podemos associar ao desejo que movimenta uma subjetividade. A semelhança é clara: define-se o objeto que se deseja, se constroem os meios e se agenciam as forças 
que determinam as velocidades dos projéteis, para enfim atualizar aquela possibilidade. $O$ projeto é então o nome dado a capacidade do ser humano de projetar seu futuro, de determinar estados virtuais pela imaginação, e que pelo uso de máquinas, se processam os meios e se aproximam os dois pontos. $O$ designer que possuir mais máquinas será o designer que terá capacidade de agenciar projetos mais híbridos e de fato atualizar, criar, e inovar por projetos complexos.

Diante da dificuldade que existe na tentativa de definir as bases conceituais e a natureza da disciplina do designer, tiramos algumas conclusões: dado o movimento dos processos, podemos dizer que os caminhos que o designer toma permeiam toda e qualquer área do saber humano. Não existem barreiras disciplinares para o movimento nômade (DELEUZE, GUATTARI, 1995) do designer, que cata do chão pedaços e une em um perfeito bricolage um objeto que porta consigo a inovação. Dada essa possibilidade de união entre saberes, podemos afirmar que o design em sua configuração epistemológica é transdisciplinar, pois tudo converge em um uno rizomático (DELEUZE, GUATTARI, 1995), todos os saberes se completam em direção a uma abordagem complexa. Contudo, apontamos uma distinção clara entre o movimento do designer e o chão por onde ele pisa. Se pensamos num ambiente transdisciplinar, a paisagem é única, e o movimento do designer é nômade, pois atravessa quaisquer fronteiras. Assim, elevando a complexidade deste movimento, podemos pensar em algo como uma indisciplinaridade: ignora qualquer território do saber. Diante de tão ousada afirmação, argumentamos que o movimento desejante é indisciplinar, é movimento constante de reterritorialização (DELEUZE, GUATTARI, 1995) sobre a própria terra, ou seja, pelo fato de ter a potência de agenciar qualquer disciplina, sua essência não pode se categorizar. $O$ sistema de saberes humanos une tudo em um, seja pela humanidade que as formula ou as finalidades que sempre serão antropogênicas. A cada fluxo transversal (indisciplinar) que um projeto agencia, uma linearidade transdisciplinar é deixada como resultado. A diferença que propomos é de que, livre de qualquer disciplina, e aqui usamos como sinônimo de regime, de ordenação, o movimento corre solto e permite ao designer propor linhas de fuga (DELEUZE, GUATTARI, 1995), pontos singulares de inovação. Um dos pilares de nossa argumentação sobre a própria conotação da atuação do designer depende do pressuposto de que, não havendo categorias disciplinares para o movimento do design, toda e qualquer atuação poderá ser alvo de processos em design.

Aqui proporemos então uma nova perspectiva sobre o design: de que ele se configura como uma atuação humana plural, e que pode se remodelar a cada momento, dependendo da problemática a ser solucionada. Não existem métodos em design, pois processos matemáticos, biológicos, sociais, todos podem ser transpostos e readequados a novas disciplinas, e o design é uma forma de se fazer isso. Toda atividade projetiva é um desafio conceitual e criativo pois coloca o designer sob cheque: quão capaz se é de criar algo coeso e coerente, sendo que não existem limites para as matérias de expressão que podem ser utilizadas? Seguindo o princípio de possível adjacente, que Steven Johnson nos apresenta, podemos entender que todo projeto abre uma nova porção de terra sobre qual os novos designers poderão criar. Estamos falando então de uma terra em constante expansão a cada nova criação. A complexidade dos projetos pode crescer cada vez mais, sempre reunindo pessoas em um projeto colaborativo, reunindo epistemes diferentes para poder propor uma problematização complexa e consequente instrumentalização para o processo de atualização.

Dessa forma, podemos responder a nossa hipótese inicial da seguinte forma: os processos em design são categorizados pelas formas de construção e atualização de existências. O projeto é ferramenta de abertura para a complexidade pelo processo de virtualização, expansão de possíveis, 
afunilamento de escopo e criação de um sistema de máquinas responsável por agenciar o processo. Se não existem limites para quais matérias poderão ser utilizadas na assemblage, podemos concluir que, livre de disciplinas, o design se torna um método de agenciamento de desejos pela reversão ontológica de objetos; reversão através do ciclo virtualização-atualização, problematização-solução. Qualquer processo que se utilize desse modus operandi poderá ser configurado enquanto processo em design. A delimitação de atuações para o design apenas segmenta as possibilidades de conexões entre as diversas áreas do saber. Assim, podemos dizer que as bases teóricas para o design sempre serão transdisciplinares, mas seu movimento, seu processo, é indisciplinar por atravessar as fronteiras como se elas não existissem. Essa proposta abre margem para que se pense o design como processo de atualização de complexidades virtuais pelo uso de máquinas. O domínio do design enquanto ferramenta significa que qualquer processo pode ser agenciado intencionalmente, significa que o homem adquiriu domínio sobre o tempo e sabe manipulá-lo a seu bel prazer. Que em qualquer presente, um futuro pode ser projetado, e que dado o agenciamento produtivo, diversas máquinas serão reunidas - sejam pessoas que executem tarefas, máquinas elétricas, naturais - para que os projetos, entre si e para com si, produzam determinado objeto, mirado antes mesmo dos meios serem estruturados. $O$ horizonte se expandiu para revelar que além do vale do agora, o futuro será elemento intrínseco da atuação de qualquer designer.

\section{Referências}

BAUDRILLARD, Jean. Simulacros e Simulação. Tradução Maria João da Costa Pereira - Lisboa: Editora Relógio d'Água, 1991.

BECCARI, Marcos. Articulações simbólicas: uma nova filosofia do design - Teresópolis, RJ: 2AB, 2016.

BECCARI Marcos; PORTUGAL Daniel; PADOVANI Stephania. Seis eixos para uma filosofia do Design. Revista (online). Rio de Janeiro: v. 25 | n. 1 [2017], p. 13 - 32 | ISSN 1983-196X

BORGES, Lucillia. Design Desejante: a dobra como espaço e(ntr)e, 2008. 224p. Tese (Doutorado em Comunicação e Semiótica) - Pontifícia Universidade Católica de São Paulo, São Paulo. Disponível em « https://issuu.com/luciliaborges/docs/tese >. Acesso em 27/10/2017.

DELEUZE, Gilles. Diferença e Repetição. Tradução de Luiz Orlandi e Roberto Machado - Lisboa: Relógio d'Água, 2000.

O ato de criação. Palestra proferida em Paris em 1987, transcrita e publicada em Folha de São Paulo, 27 jun 1999, Caderno Mais!, p. 4-5.

O abecedário de Gilles Deleuze. Entrevista com G.Deleuze. Editoração: Brasil, Ministério da Educação, TV Escola, 2001. Paris: Éditions Montparnasse, 1997, VHS, 459min

DELEUZE, Gilles; GUATTARI, Felix; O que é a Filosofia? São Paulo: Editora 34, 1993.

Mil platôs: Capitalismo e esquizofrenia, vol 1; tradução de Aurélio Guerra Neto e Célia Pinto Costa Rio de Janeiro: Editora 34, 1995.

Mil platôs - capitalismo e esquizofrenia, vol. 3; tradução de Aurélio Guerra Neto etalii. - Rio de Janeiro: Ed. 34, 1996.

Mil platôs - capitalismo e esquizofrenia, vol. 5; tradução de Peter Pál Pelbart e Janice Caiafa. - Rio de Janeiro: Ed. 34, 1997..

O anti-Édipo: capitalismo e esquizofrenia; tradução de Luiz B. L. Orlandi. - São Paulo: Ed. 34, 2010. DENIS, Rafael. Design, cultura material e o fetichismo dos objetos. In.: Revista Arcos.

FOUCAULT, Michel. As palavras e as coisas: uma arqueologia das ciências humanas. Tradução de Salma 
Tannus Muchail - São Paulo: Martins Fontes, 1992.

GALVÃO, Cleyton. Os sentidos do termo virtual em Pierre Lévy. Revista (online). LOGEION: Filosofia da informação, Rio de Janeiro, v. 3 n. 1, p. 108-120, set./ mar. 2017.

GUATTARI, Félix. Caosmose: um novo paradigma estético. Tradução de Ana Lúcia de Oliveira e Lúcia Claudio Leão - São Paulo: Editora 34, 1992.

As três ecologias. Tradução Maria Cristina F. Bittencourt. Campinas: Papirus, 1990.

LÉVY, Pierre. $O$ que é o virtual? Tradução de Paulo Neves. São Paulo: Editora 34, 2011.

MORIN, E. Introdução ao pensamento complexo. Porto Alegre: Sulina, 2015

PIGNATARI, Décio. Informação, Linguagem, Comunicação. São Paulo: Editora Cultrix, 1981.

ROSSI, Dorival. Transdesign: Folias da linguagem e anarquia da representação, 2003. Tese (Doutorado em Comunicação e Semiótica - Signo e Significação nas Mídias) Programa de pós-graduação em Comunicação e Semiótica, Pontifícia Universidade Católica de São Paulo, São Paulo.

VIEIRA, Jorge. $O$ universo complexo e outros ensaios - Rio de Janeiro: Rizoma, 2015.

ZOURABICHVILI, François. O Vocabulário de Deleuze. Tradução André Telles - Rio de Janeiro: UNICAMP, 2004. 